\title{
XXIX. Heat produced by moistening pulverized bodies
}

\section{Tito Martini}

To cite this article: Tito Martini (1897) XXIX. Heat produced by moistening pulverized bodies , Philosophical Magazine Series 5, 44:267, 205-206, DOI: 10.1080/14786449708621053

To link to this article: http://dx.doi.org/10.1080/14786449708621053

曲 Published online: 08 May 2009.

Submit your article to this journal ๘

Џ Article views: 2

Q View related articles ¿ 


\section{$\left[\begin{array}{ll}205 & ]\end{array}\right.$}

\section{Heat produced by Moistening Pulverized Bodies*.}

$B y$ Trto Martini $\dagger$.

THE phenomena discovered by Pouillet $\ddagger$, regarding the 1 production of heat by the moistening of porous bodies, are well known, and since Pouillet many experiments have been made by Cantoni $\$$, Melsens $\|$, Chappuis 1 , E. Wiedemann**, and Meissnert+.

Notwithstanding the investigations of these philosophers, however, I believe that it may be of some interest to publish the results of my own researches in this direction, which are more extended than those of the savants referred to.

Among the numerous results contained in my paper I will select the most complete, that is to say, those concerning chemically pure animal charcoal, believing that such important manifestations are due to a different method of experimenting adopted by me; consisting of an arrangement whereby the liquid ascended to the powder, which was placed in a glass tube separated from it by a piece of light linen cloth.

TABLE (8th of the original paper).

\begin{tabular}{|c|c|c|c|c|c|}
\hline Name of the liquid, & $\begin{array}{l}\text { Temp. of } \\
\text { the air. }\end{array}$ & $\begin{array}{l}\text { Temp. of } \\
\text { the liquid. }\end{array}$ & $\begin{array}{c}\text { Temp. of } \\
\text { the charcoal. }\end{array}$ & Max. temp. & $\begin{array}{l}\text { Increase of } \\
\text { the temp. }\end{array}$ \\
\hline Distilled water ......... & $18 \cdot 10$ & 17.51 & 17.92 & 3350 & $15 \cdot 58$ \\
\hline Absolute alcohol ...... & $18 \cdot 09$ & $\mathbf{1 7} \cdot 82$ & $18 \cdot 28$ & $35 \cdot 75$ & $17 \cdot 47$ \\
\hline Sulphuric ether & $17 \cdot 10$ & $16 \cdot 82$ & $17 \cdot 20$ & $34 \cdot 70$ & $17 \cdot 50$ \\
\hline Acetic ether ............. & $18 \cdot 30$ & $18 \cdot 22$ & $18 \cdot 48$ & $37 \cdot 42$ & 18.94 \\
\hline Benzine .............. & $18 \cdot 30$ & $18 \cdot 52$ & $18 \cdot 70$ & $36 \cdot 30$ & 1760 \\
\hline Bisulphide of carbon... & $17 \cdot 10$ & $17 \cdot 12$ & $17 \cdot 50$ & $38 \cdot 10$ & $20 \cdot 60$ \\
\hline
\end{tabular}

Owing to this mode of conducting the experiment, I was enabled to observe that when the rise of temperature was not

* "Intorno al calore che si sviluppa nella umettazione delle polveri," Atti del $R$. Istituto Veneto, t. viii. serie 7, Maggio 1897.

+ Communicated by the Author.

† Annales de Chimie et de Physique, $2^{\mathrm{me}}$ série, t. xx. p. 411.

\$ Atti del R. Istituto Lombardo, Maggio 1866.

II Ménoives de l'Académie royale de Belgique, t. xxiii. (1883).

If Wiedemann's Annalen, t. xix. p. 21 (1883).

** Ibid. t. xxy. p. 145 (1885). 
great (in the case of mineral powders) the powder became a soft paste; but that with a great increase of temperature (in the case of charcoal, sawdust, \&c.) the powder was transformed into a consistent mass resembling stone.

This curious phenomenon would tend to confirm the opinion that the production of heat is due to the molecular energy being transformed into thermal energy.

In another communication I will give further notice in regard to this interesting question.

Venice, June 1897.

XXX. On Proofs of a Theorem in Wave-motion.

To the Editors of the Philosophical Magazine. GentLemen,

T CRAVE permission to correct an error on p. 101 of my letter in the July number of the Philosophical Magazine, where 1 described the waves in each of the equations

$$
\begin{aligned}
& \xi=\mathrm{F}_{1}(x, y, z, t), \\
& \eta=\mathrm{F}_{2}(x, y, z, t), \\
& \zeta=\mathrm{F}_{3}(x, y, z, t) .
\end{aligned}
$$

(when extended to all space and expanded by Mr. Preston's valuable corollary to Fourier's theorem) as waves that are non-natural in two respects. In fact, they are non-natural in only one of these respects. The wave-lengths, in the case there dealt with, do not range in these equations from infinity down to cypher as I supposed when writing the letter, but are of one wave-length, as may be proved by a slight modification of the well-known theorem given on p. 435 of my second paper on Microseopic Vision in the Phil. Mag. for November, 1896. The waves of each of the above equations are non-natural, $i$.e., merely kinematical, in consequence of their transversals standing in impossible positions.

Nevertheless, as is the case with every kinematical resolution when applied to a real motion, the resultant of combining the three kinematical components in any one direction, must of necessity give the real undulation in that direction if there be any such. 'That there is a real undulation I had previously shown by MacCullagh's method of proof, and further that it consists of uniform plane waves of the kind which the medium can propagate unchanged. 